\begin{tabular}{|c|c|c|}
\hline 2 & $\begin{array}{l}\text { International Journal of Current Research in } \\
\text { Biosciences and Plant Biology }\end{array}$ & $=$ \\
\hline $\begin{array}{l}\text { EXCELLENT } \\
\text { PUBLISHERS }\end{array}$ & $\begin{array}{c}\text { Volume } 5 \bullet \text { Number } 5 \text { (May-2018) } \bullet \text { ISSN: 2349-8080 (Online) } \\
\text { Journal homepage: } \underline{\text { www.ijcrbp.com }}\end{array}$ & wwr.jectpo conm \\
\hline
\end{tabular}

Original Research Article

doi: https://doi.org/10.20546/ijcrbp.2018.505.001

\title{
Preliminary Investigation on the Minimal Population of Magnolia pilocarpa in the Dabie Mountain Area of Hubei Province
}

\author{
Sijia Zhu' ${ }^{1}$, Aiguo Zhen ${ }^{2}$, Shan Yang ${ }^{3}$, Qin Xie ${ }^{4}$, Dong Wang', \\ Chengshi Huang ${ }^{1}$ and Die $\mathrm{Hu}^{1 *}$
}

${ }^{1}$ College of Horticulture and Landscape Architecture, Yangtze University, Jingzhou-434025, Hubei, China

${ }^{2}$ Yingshan County Forestry Bureau, Huanggang-438700, Hubei, China

${ }^{3}$ Wuhan Pindao Architectural Garden Engineering Co. Ltd., Wuhan-430040, Hubei, China

${ }^{4}$ New World Development (Wuhan) Gardening and Greening Engineering Co. Ltd., Wuhan-430040,

Hubei, China

*Corresponding author

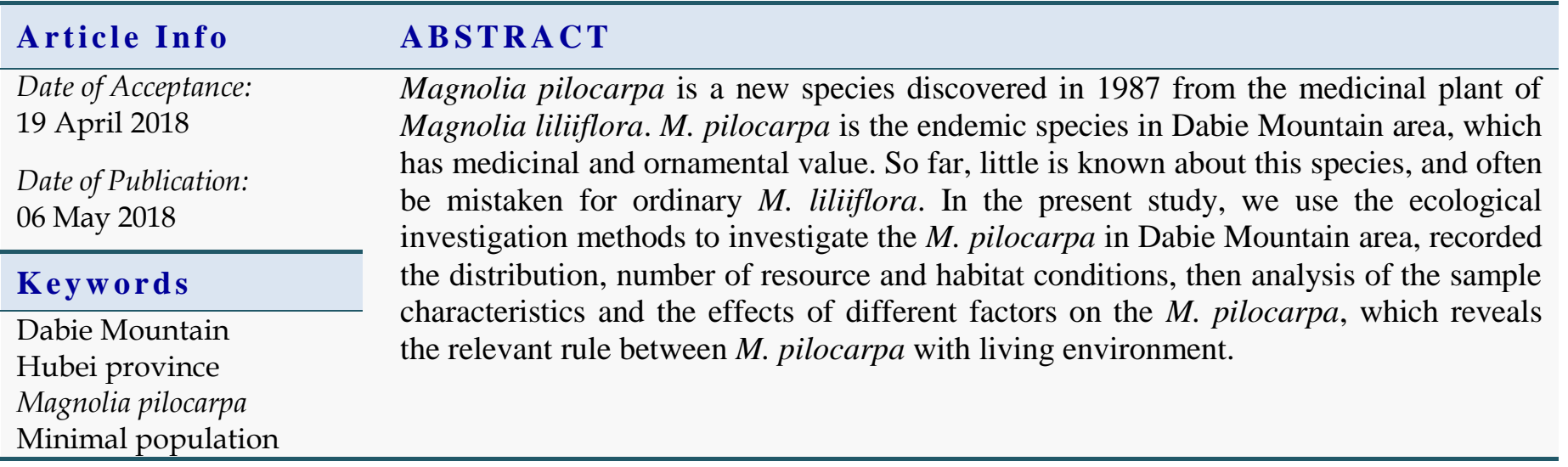

\section{Introduction}

Minimal population plant is a kind of endangered wild plant with geographical narrowing of distribution, few population and individual quantity. The population is degenerating and the number of individuals continues to decrease which have been lower than the stable survival threshold because of the stress interference from external factors in a long term (State Forestry
Administration, 2011). M. pilocarpa belongs to Magnolia, Magnoliaceae. It is a kind of deciduous tree with bark taupe and height between 12 and 15 meters $(\mathrm{Fu}, 2001)$. The leaves are in the shape of obovate or broadly obovate, $10-17 \mathrm{~cm}$ long, $8-11 \mathrm{~cm}$ wide, and the apex is wide and round with dent, short and acute. The base of leaves is in the shape of wedges or wide wedges and in the color of dark green above, light green below. There are about 9-11 lateral veins on each side. The length of 
stipule scars is half of that for petiole. The flowering phase of $M$. pilocarpa is from March to April and the fruiting season is from September to October (Wang et al., 2003).

M. pilocarpa is a new species being found in $M$. liliiflora in 1987(Zhao et al., 1987). It has been listed as a small population plant in Hubei province owing to the small quantity and the narrow habitat. In order to find out total number, distribution and growth of $M$. pilocarpa in Hubei province, we carried out a systematic investigation and objective analysis. As is shown, M. pilocarpa has only been found in the Dabie mountain area in Huanggang, so the author investigated $M$. pilocarpa in the Dabie Mountains of Hubei province.

\section{Geographical environment of the Dabie Mountains}

The Dabie Mountains are the watershed between the Huai River and the Yangtze River, located in border areas of Henan, Anhui and Hubei province, latitude $\mathrm{N} 30^{\circ} 10^{\prime} \sim \mathrm{N} 32^{\circ} 30^{\prime}$, altitude $\mathrm{E} 112^{\circ} 40^{\prime}$ $\sim \mathrm{E} 117^{\circ} 10^{\prime}$. Generally, the altitude is $500 \sim 800 \mathrm{~m}$, and the main part of the mountain is $1500 \mathrm{~m}$ above sea level. The elevation of the main peak is $1729 \mathrm{~m}$. The mountain forest area accounts for $15 \%$ of the whole mountain area, the rest is low mountain and hilly, the mountain valley is wide open, and there are floodplain and terrace plain. The Dabie Mountain is a warm and humid monsoon climate zone in the north subtropical region, with typical mountain climate characteristics and superior forest microclimate, abundant rainfall and mild climate. Annual average temperature is $12.5^{\circ} \mathrm{C}$, average precipitation is $1832.8 \mathrm{ml}$, annual precipitation days is $161 \mathrm{~d}$, air relative humidity is $79 \%$ on average, elevation difference is big, and Dabie Mountain forest vegetation changes obviously.

\section{Materials and methods}

\section{The survey of time}

From January to June in 2017, a comprehensive investigation has been conducted in Luotian
County, Yingshan County and Tuanfeng County in Huanggang City.

\section{The research methods}

According to the research method of ecology, due to the sparse distribution of the $M$. pilocarpa, there is no large area of community distribution, so we take the measurement method to investigate. Measurement method: it is suitable for narrow and small distribution area, and the number of plant population is relatively rare, which is convenient for direct counting of target species ( $\mathrm{Li}$ et al., 2016). After a lot of investigation, more complete information is accumulated. The resources, distribution and scope of $M$. pilocarpa are clear.

\section{Measurement index}

The measurement indexes of the single plant $M$. pilocarpa include the ground diameter, the diameter of the chest, the crown width and the height of the tree. Sample area habitat measurements include: geographic coordinates, elevation, canopy density, coverage, slope, slope direction, soil type, and the record-nation of the surrounding associated species: the herb layer, shrub layer, the condition of the tree layer, at the same time record-nation of the growth situation of target species (Sun et al., 2016).

\section{The data statistics of population basic characteristic}

A comprehensive survey was conducted on all $M$. pilocarpa in the Dabie Mountain area of Hubei Province. According to the classification criteria of $H>5 \mathrm{~m}, 1 \mathrm{~m}<\mathrm{H}<5 \mathrm{~m}$ and $\mathrm{H}<1 \mathrm{~m}$, the individuals of $M$. pilocarpa are divided into the main forest layer, succession layer and update layer (Liu, 2007), which is used to calculate the quantitative characteristics of $M$. pilocarpa. After summary of the investigation data, we made statistics different slope direction, slope position, altitude of different levels of $M$. pilocarpa, and compared the number of $M$. pilocarpa under different habitats, different ecological factors and wild $M$. pilocarpa distribution relationship. 
The classification standard of diameter class structure for (Peng 1993; Ma et al., 2013): seedling height $\mathrm{H}<100 \mathrm{~cm}$ is I seedling; Diameter at breast height $(\mathrm{DBH})<3 \mathrm{~cm}$ is II young trees; 3 $\mathrm{cm}$ diameter or $\leq \mathrm{DBH}<12 \mathrm{~cm}$ for buck III level; Diameter at breast height $12 \mathrm{~cm} \leq \mathrm{DBH}<20 \mathrm{~cm}$ for buck IV level; Diameter at breast height (DBH) $\geq 20 \mathrm{~cm}$ for $\mathrm{V}$ trees.

\section{Results and discussion}

\section{The overall distribution of the $M$. pilocarpa}

The $M$. pilocarpa is scattered. By referring to data and field research, $M$. pilocarpa which in the Dabie mountains of Hubei province, mainly focused on the five points of Qing Tai Guan forest farm in Luotian county, the scenic spot of Baodao feng, the forest farm of Huang Shizhai, Wujia mountain forest farm in Yingshan county, and Daqi mountain forest farm in Tuanfeng County. In total, there are $54 \mathrm{M}$. pilocarpa in the five sample area. Among them, respectively, there are 23 strains and 18 strains in the Jiu Zihe town and the scenic spot of Baodao feng in Luotian County. With the help of local forestry authorities, a full investigation was carried out.

\section{Distribution of $M$. pilocarpa in different slopes}

According to the sample indicated, there are 54 strains of $M$. pilocarpa, of which 35 were grown in sunny slope and 19 in the shady slope. According to the statistics on the number of $M$. pilocarpa in different slopes and different levels, such as main forest floor, update layer and succession layer, $M$. pilocarpa is most widely distributed in sunny slope, which shows that $M$. pilocarpa is more suitable for living under sunny conditions.

Whether it is in the sunny slope or in the shady slope, the number of the updated layers is 0 , and even the seedlings are 0 . From which we can known that the seed germination of $M$. pilocarpa is difficult, and it is not very adaptable to the external environment. The distribution of $M$. pilocarpa in different slopes is shown in Table 2.

\section{Diameter Distribution of $M$. pilocarpa in Different Sample Areas}

The diameter of $M$. pilocarpa in survey areas, for example in the Fig. 1 in which the characteristics of $M$. pilocarpa in each area show distinct differences. In Jiuzi River plot, the majority are big trees, according for $74 \%$ while Middle-aged tree take up 21.7\%, without seedlings. In Baodao feng scenic spot, trees of all grades are distributed and the number of them is not much different. The number of individual seedling according for $0 \%$ of the total number of the plots, while the young trees takes up $27.8 \%$ and the adult trees take up $72.2 \%$. In Huang Shizhai forest form, there are only 2 big trees as well as in the Daqishan forest form. However, in the Wujiashan forest farm, the majority are adult tree and without seedlings. The $M$. pilocarpa surveyed in Dabie mountain this time, they are mostly big trees, no seedlings, and are distributed sparsely. It is obvious in the Fig. 1 that the distribution in the Baodao feng scenic spot is the most evenly and the community level is the most completely. This shows that in the interference of external environment especially the action of human, the growth of $M$. pilocarpa is becoming more and more difficult the percentage of germination is low, the growth of seedlings become difficult, and the situation of extinction is more and more serious.

The relationship between the growth of $M$. pilocarpa and the slope aspect

It can be seen from the slope aspect that the distribution of $M$. pilocarpa in the survey areas changes with the slope aspect. We can see from the table 3 that the growth of $M$. pilocarpa in the sunny slope have obvious advantages compared with that in the cloudy slope. The diameter and height of $M$. pilocarpa individual changes with the slope aspect. The average diameter in the sunny slope is $26.06 \mathrm{~cm}$ which is obviously higher than $12.86 \mathrm{~cm}$ in the cloudy slope. The average height $9.02 \mathrm{~cm}$ is also higher than $7.53 \mathrm{~cm}$. Therefore the growth of $M$. pilocarpa in sunny slope is better than that in the cloudy slope. 
Table 1. Distribution of M. pilocarpa in Dabie Mountains.

\begin{tabular}{lll}
\hline Distribution area & Latitude and longitude range & Quantity (strain) \\
\hline Luotian County Jiuzi River Town & E115 $42^{\prime}-\mathrm{E} 115^{\circ} 43^{\prime}$ & 23 \\
& $\mathrm{~N} 31^{\circ} 7^{\prime}-\mathrm{N} 31^{\circ} 10^{\prime}$ & \\
Luotian County Baodao feng Scenic Area & $\mathrm{E} 115^{\circ} 32^{\prime}-\mathrm{E} 115^{\circ} 34^{\prime}$ & \\
& $\mathrm{N} 31^{\circ} 06^{\prime}-\mathrm{N} 31^{\circ} 07^{\prime}$ & \\
\hline Luotian County Huang & $\mathrm{E} 115^{\circ} 33^{\prime} 59.43^{\prime \prime}$ & 2 \\
Shizhai Forest Farm & $\mathrm{N} 31^{\circ} 06^{\prime} 16.61^{\prime \prime}$ & 9 \\
Yinshan County Wujiashan Forest Farm & $\mathrm{E} 115^{\circ} 46^{\prime}-\mathrm{E} 115^{\circ} 47^{\prime}$ \\
& $\mathrm{N} 31^{\circ} 5^{\prime}-\mathrm{N} 31^{\circ} 6^{\prime}$ & \\
Tuanfeng County Daqi Mountain Forest & $\mathrm{E} 115^{\circ} 06^{\prime} 02.78^{\prime \prime}$ & 2 \\
Farm & $\mathrm{N} 30^{\circ} 51^{\prime} 53.11^{\prime \prime}$ \\
\hline
\end{tabular}

Table 2 Community level statistics of different slope directions of M. pilocarpa.

\begin{tabular}{lll}
\hline Slope direction & Community level & Number of strains \\
\hline Sunny slope & Main forest layer & 32 \\
& Successor layer & 3 \\
Shady slope & Update layer & 0 \\
& Main forest layer & 14 \\
& Successor layer & 5 \\
& Update layer & 0 \\
\hline
\end{tabular}

Table 3. Growth and distribution of M. pilocarpa in different slope directions.

\begin{tabular}{llll}
\hline Slope direction & Number of strains & Average DBH $(\mathbf{c m})$ & $\begin{array}{l}\text { Average tree } \\
\text { height }(\mathbf{m})\end{array}$ \\
\hline Sunny slope & 35 & 26.06 & 9.02 \\
Shady slope & 19 & 12.89 & 7.53 \\
\hline
\end{tabular}

Table 4. Growth and distribution of $M$. pilocarpa in different altitudes.

\begin{tabular}{llll}
\hline Altitude (m) & Number of strains & Average DBH (cm) & $\begin{array}{l}\text { Average tree height } \\
(\mathbf{m})\end{array}$ \\
\hline $\mathrm{H}>1000$ & 10 & 16.05 & 5.83 \\
$800 \leq \mathrm{H} \leq 1000$ & 8 & 23.31 & 8.35 \\
$600 \leq \mathrm{H}<800$ & 23 & 24.63 & 9.41 \\
$400 \leq \mathrm{H}<600$ & 5 & 22.4 & 8.42 \\
$\mathrm{H}<400$ & 8 & 20.02 & 7.23 \\
\hline
\end{tabular}




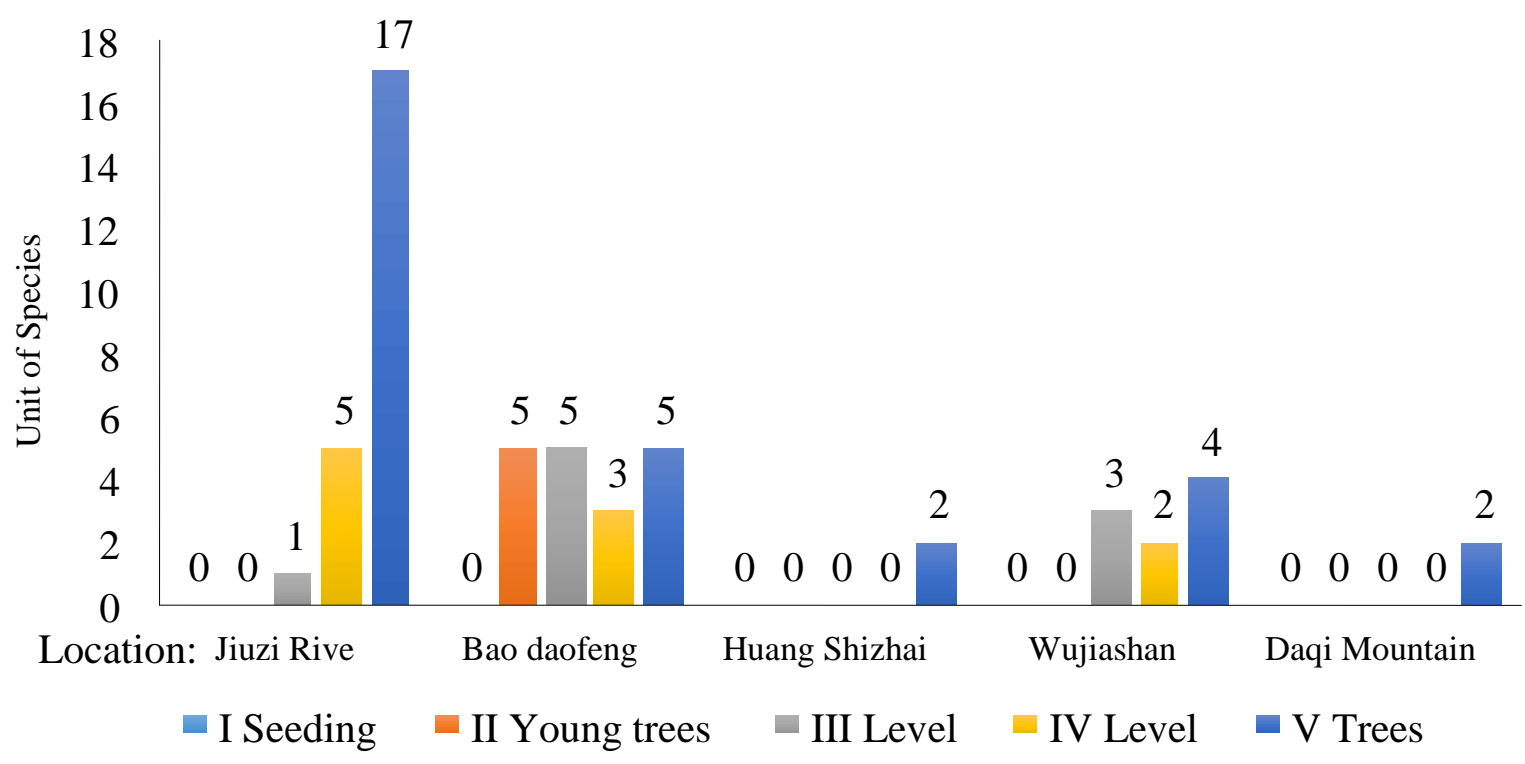

Fig. 1: Structure chart of various big and small steps of $M$. pilocarpa in Dabie Mountain.

\section{The relationship between the growth potential of the M. pilocarpa and the different altitudes}

From the perspective of the altitude, the distribution of the individuals in the survey sample is different due to the changes in altitude (Table 4). Most of M. pilocarpa are located between $600 \mathrm{~m}-800 \mathrm{~m}$, there are 23 strains, which accounts for $42.6 \%$ of the total. M. pilocarpa districts averagely in other altitude district. There are 10 strains in total whose height is over $100 \mathrm{~m}$. Among them, there are 5 seedlings with average chest diameter of $1.5 \mathrm{~cm}$ and average height of $2 \mathrm{~m}$, and there are no obvious distinctions in each elevation so it can be concluded that the altitude has weak effects on the growth of M. pilocarpa.

With the rapid increase of population and the continuous enhancement of human activities, more and more natural vegetation have been destroyed, biological diversity has also fallen sharply, and many species are now endangered. Endangered species are the result of a combination of external and internal factors. External factors mainly include fragmentation and loss of habitat, global climate change, various natural disasters and human factors, etc. These factors directly affect the living condition of the species, which is the direct cause of the endangered species. The internal factors mainly include adaptation, viability, reproduction and the failure of heritability. These factors seriously threaten the growth and reproduction of the species (Xu, 2016), which is the important cause of the endangered species. Therefore, it is a precondition for effective protection of plants to find out the endangering mechanism.

\section{The cause of M. pilocarpa dying}

According to field investigations, most villagers in Luotian and Yingshan did not know M. pilocarpa, even less aware of its value and importance, and did not protect it as a precious tree species, and even conducted extensive logging. In addition, from the present situation and historical changes of the distribution area of $M$. pilocarpa, human beings to meet their own survival needs, the phenomenon of man-made wasteland and deforestation is very serious, man-made severe disturbance led to a serious loss of natural regeneration ability of $M$. pilocarpa, and the distribution area is also sharply reduced. The 
distribution pattern has undergone significant changes and is now mainly scattered.

The ecological adaptation range of $M$. pilocarpa is very narrow, and it is mainly distributed in the Dabie Mountains area of Hubei Province. It is suitable for the subtropical monsoon mountain climate and its distribution area is limited.

In addition, $M$. pilocarpa population is poor in its reproductive ability, and its seeds are easily destroyed and lost a part after landfall. The seeds of $M$. pilocarpa are very good food for birds. Many seeds have already been eaten by birds when they have just been ripe on the trees.

\section{Protection measures and suggestions}

\section{Investigation on wild $M$. pilocarpa}

Firstly, a targeted investigation of the wild $M$. pilocarpa resources should be carried out to ascertain the distribution, quantity, habitat, and protection of the wild $M$. pilocarpa resources and establish the $M$. pilocarpa Resource Information Base. The dynamic monitoring of the region with more concentrated distribution and scientific implementation of the protection of wild plants are the groundwork for further development of artificial breeding resources and promotion of sustainable development of resources (Huang, 2003).

\section{Strengthening the management of the legal system and implementing universal protection}

To avoid the destruction of the habitat of $M$. pilocarpa and other illegal acts that occurs due to the temptation of the economy. We should implement strictly the "wild plants protection regulation" and the "forest law", effectively protecting the $M$. pilocarpa and preventing the unlawful action. $M$. pilocarpa trees should be listed for protection and the management charge should be determined. Popularizing the education of endangered plants protection at the same time, increasing the $M$. pilocarpa habitat protection, making the whole people participate in the protection (Yang et al., 2014).

\section{Establishing the reserve and the $M$. pilocarpa germplasm resource nursery}

It is better to protect the resources of $M$. pilocarpa in the wild in situ. Then we should establish the $M$. pilocarpa resource reserves to improve the habitat gradually and expand the population of $M$. pilocarpa. At the same time, the germplasm resources nursery of $M$. pilocarpa in Dabie Mountain Luotian will be established. By means of introduction and cultivation, the germplasm resources can be preserved for a long time, and the application of artificial cultivation and popularization will be actively carried out so as to ensure the sustainable development of the resource utilization of $M$. pilocarpa to achieve the sustainable development (Zhen et al., 2016).

\section{Enhancing scientific research}

We are actively carrying out basic research on the morphology, cytology and molecular biology of the magnolia and further clarifying the reasons for the near-death of $M$. pilocarpa. The selection of the best varieties are achieved by rod insertion, tissue culture, cross breeding and molecular marker assisted selection, which is able to provide practical measures for the protection and exploitation of the resources of $M$. pilocarpa (Lin, 2008).

\section{Conflict of interest statement}

Authors declare that they have no conflict of interest.

\section{Acknowledgement}

This work was supported by the national second survey for key protected wild plant resources (Protect of minimal population in Hubei province). Thank you for great support and assistance of forestry bureau in Luotian County, Yingshan County and Tuanfeng county of Huanggang, Hubei Province. 


\section{References}

Fu, D. L., 2001. Study on the resources varieties and new plant breeding of Magnolia liliiflora. Doctoral thesis, Zhongnan Forestry University.

Huang, H. Y., 2003. Present situation and prospect of wild plant protection in China. Guangxi Forest. Sci. 32(2), 107-110.

Li, J. L., Sun, B., Fei, Y., Zhou, M.Q., Zhou, C. Y., 2016. A preliminary study on the population and biological community characteristics of natural Phoebe zhennan in Hubei Lichuan. J. Yangtze Univ. (Natural Sci. Edn.). 13(33), 1115.

Lin, L., 2008. Discussion on the deficiencies of legal protection of wild plant resources in China and the counter measures. J. Northwest A \& F Univ. (Social Sci. Edn.). 8(1), 109-113.

Liu, T., 2007. Study on Population Ecology of Natural Taxus cuspidata in Dongbei. Doctoral thesis, Northeast Forestry University, Haerbin.

Ma, Y. P., Chen, G., Grumbine E, D., et al., 2013. Conserving plant species with extremely small population (PSESP) in China. Biodiv. Conserv. 22, 803-809.

Peng, S. L., 1993. A discussion on the fluctuation of plant community. Chin. J. Appl. Ecol. 4(2), 120-125.
State Forestry Administration, 2011. Project planning of conservation and protection of wild plants in minimal region of China (2011-2015) State Forestry Administration, Beijing.

Sun, Y. F., Zhang, Y., 2013. Discussion on investigation methods of wild plant resources in Heilongjiang Province. Prot. Forest Sci. Technol. Sep. 87.

Wang, Y. L., Li., Y., Zhang, S. Z., et al., 2003. RAPD relationship of several Magnolia plants. J. Hortic. 30(3), 299-302.

$\mathrm{Xu}$, Z. D., 2016. Study on the population and biological community characteristics of natural Phoebe zhennan in Hubei Lichuan. Doctoral thesis, Yangtze University, Hubei.

Yang, W. Z., Kang, H. M., Xiang, Z. Y., Zhang, S. S., Peng, Z. N., 2014. Methods and techniques for conserving wild plant species with extremely small population. J. West China Forest. Sci. 5, 24-29.

Zhao, Z. Z., Xie, Z. W., Shen, J., 1987. A new name for a new species and a variant of medicinal Magnolia liliiflora. Acta Pharmaceut. Sin. 22(10), 777-780.

Zhen, A. G., Li, S. S., Yang, J. J., Yang, F. N., Fang, Y. P., 2016 Investigation of rare and endangered plants in Yingshan town of Hubei Province. J. Huang. Normal Univ. 36(6), 37-40.

\section{How to cite this article:}

Zhu, S., Zhen, A., Yang, S., Xie, Q., Wang, D., Huang, C., Hu, D., 2018. Preliminary investigation on the minimal population of Magnolia pilocarpa in the Dabie Mountain area of Hubei Province. Int. J. Curr. Res. Biosci. Plant Biol. 5(5), 1-7. doi: https://doi.org/10.20546/ijcrbp.2018.505.001 